EESTI NSV TEADUSTE AKADEEMIA TOIMETISED. 27. KOIDE

GEOLOOGIA. 1978, NR. 4

ИЗВЕСТИЯ АКАДЕМИИ НАУК ЭСТОНСКОП ССР. ТОМ 27

ГЕОЛОГИЯ. 1978, № 4

\title{
О ПРИМЕНЕНИИ РАСХОДОМЕТРИИ ПРИ РАСЧЛЕНЕНИИ ГИДРОГЕОЛОГИЧЕСКОГО РАЗРЕЗА КАРБОНАТНОЙ ТОЛЩИ НА ПАНДИВЕРЕСКОЙ ВОЗВЫШЕННОСТИ
}

В последнее время при расчленении гидрогеологического разреза широкое применение нашел метод расходометрии (Гершанович, 1972; Плотников, 1972), который заключается в том, что с помощью глубинных расходомеров в пробуренной скважине, соединяющей множество водоносных интервалов, определяется расход воды вдоль ствола скважины. Обычно этот метод применяется при естественном уровне воды в скважине и при одной или нескольких ступенях его изменения путем откачек, самоизлива или налива. Результаты исследований, проведенных при естественном уровне воды в условиях соединения скважиной нескольких водоносных зон с различными гидравлическими характеристиками, отражают состояние возбуждения одних зон другими.

В настоящей статье приводятся результаты работ, проведенных Управлением геологии СМ ЭССР в районе Пандивереской возвышенности при разведке подземных вод и крупномасштабной гидрогеологической съемке с использованием расходометрии. В исследованиях использовался расходомер Т СР-70, представляющий собой вертушку, с помощью которой измерялись скорость и направление потока воды в стволе скважины. Полевые работы выполнены и расходограммы отдельных скважин составлены К. Дементьевым. Керны скважин детально описаны Т. Ланг.

Расходометрические исследования, проведенные в 43 скважинах на Пандивереской возвышенности, показывают приуроченность водоносных зон ко всем выделенным в настоящей работе стратиграфическим подразделениям (рис. $1-3)$. Отдельные зоны водопритоков (поглощения) сопоставляются между собой только в пределах определенных участков с расстояниями между скважинами не более 500 м (скв. 196, 197, 198). Если скважины отстоят друг от друга на $2-3 \kappa м$, возможности сопоставления отдельных водоносных зон обычно нет. Поэтому расчленение гидрогеологического разреза на относительно слабопроницаемые и водоносные слои в пределах какого-либо участка представляется возможным только на основании статистической обработки данных расходометрин.

В данной работе отдельным водоносным слоем считается обнаруженная в скважинах с помощью расходометрии водоотдающая или водопоглощающая зона. Слои с многократным чередованием таких зон без явного доминирования в разрезе проницаемых пород над водонепроницаемыми М. Е. Альтовский (1960) называет водоносными слоями. Такой подход к определению водоносных слоев, по мнению автора, позволяет наиболее точно выявить особенности гидрогеологического строения описываемой террцтории. Условно мы считаем, что если в пределах како- 

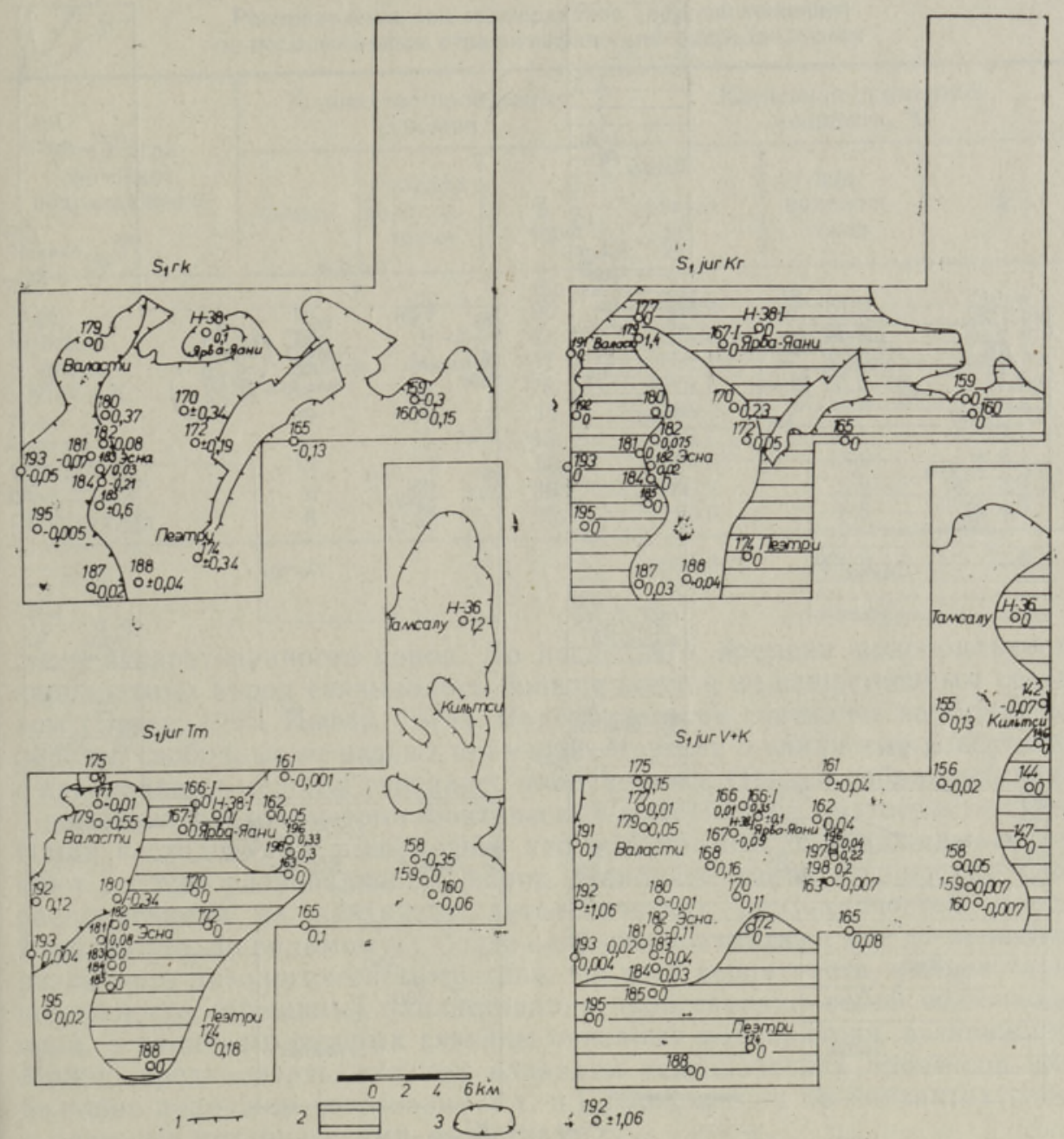

Рис. 1. Схемы обобщенных водопритоков силурийского водоносного комплекса. 1 - контур распространения, 2 - участки распространения практически безводных пород, 3 - участки с преобладанием водопоглощения, 4 - скважина, причем сверху ее номер, справа - обобщенный водоприток, $\Lambda /$ сек; минус - зона водопоглощения, плюс и цифры без знака - зона водопритока.

го-то стратиграфического подразделения в большинстве (более $50 \%$ ) скважин с помощью расходометрии установлено наличие зон притока (поглощения), такие горизонты или пачки называются водоносными, в противном случае ( $50 \%$ или меньше) они относятся к относительно слабопроницаемым (табл. 1). Мощность зон поглощения или притока равна $1-6$, обычно $1-2$ м.

Как показывают расходометрические исследования, водоносные зоны составляют из суммарной исследованной мощности гидрогеологического разреза, равной 1876 погонным метрам, лишь 14,8\%. Остальную часть разреза можно считать практически безводной в отношений гравитационной воды. В основном зоны водопритоков приурочены к райккюласкому горизонту $\left(\mathrm{S}_{1} \mathrm{rk}\right)$, к варболаской свите юуруского горизонта $\left(\mathrm{S}_{1} \mathrm{jurV}+\mathrm{K}\right)$ и к адилаской пачке пиргуского горизонта $\left(\mathrm{O}_{3} \mathrm{prgA}\right)$. На исследованном участке в $78-95 \%$ скважин водопритоки обнаружены именно в этих 


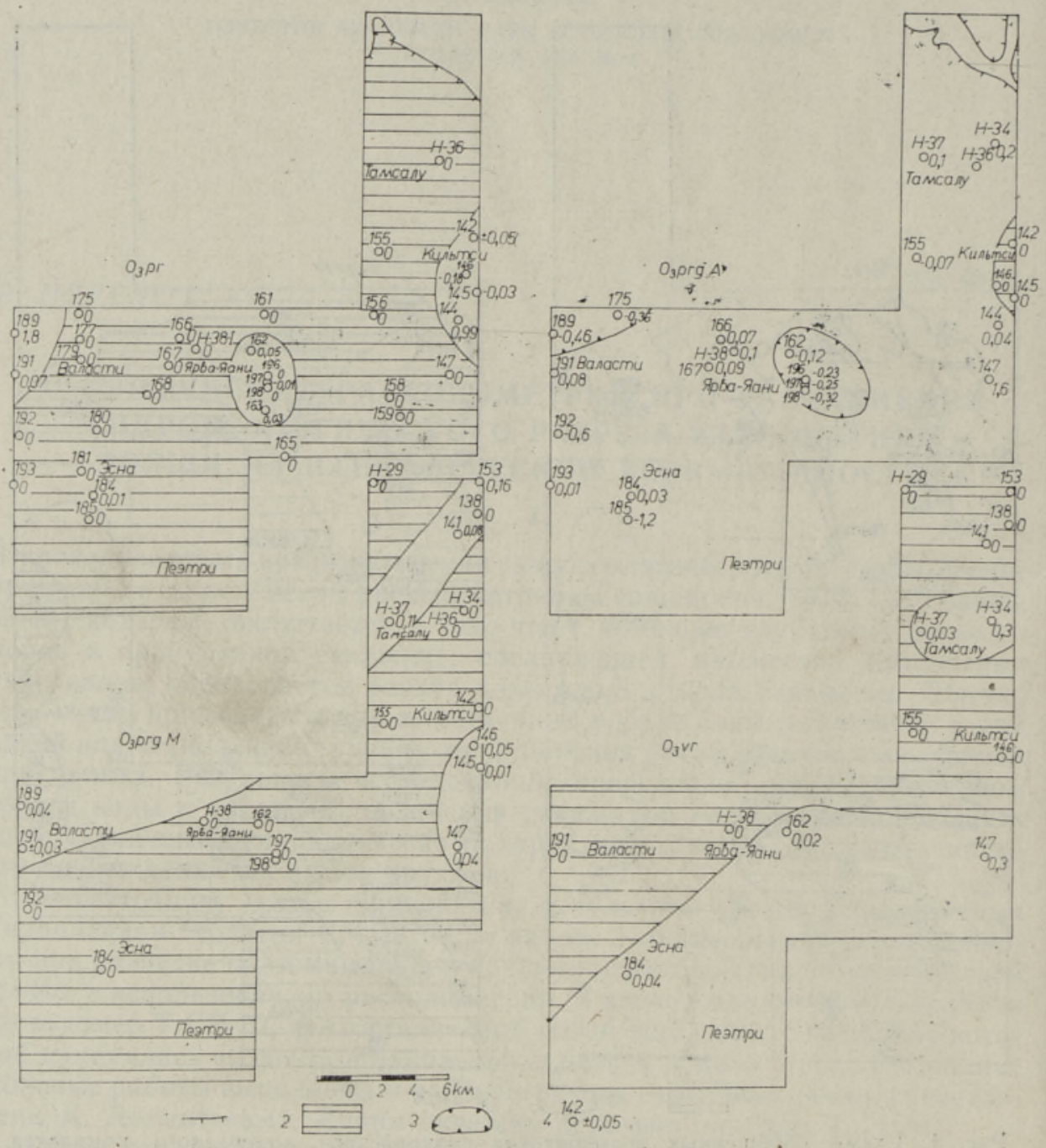

Рис. 2. Схемы обобщенных водопритоков ордовикского водоносного комплекса. Обозначения см. на рис. 1 .

стратиграфических подразделениях (рис. $4 a$, табл. 1). Значительно реже установлены зоны водопритоков в каринуской пачке юуруского горизонта $\left(\mathrm{S}_{1} \mathrm{jur} \mathrm{Kr}\right)$, в поркуниском $\left(\mathrm{O}_{3} \mathrm{pr}\right)$ и вормсиском $\left(\mathrm{O}_{3} \mathrm{vr}\right)$ горизонтах. Аналогичным образом распределяются мощности водоносных зон.

Отдельные экстремально высокие показатели водопритоков могут в некоторой степени искажать общую картину распределения обобщенных водопритоков, под которыми понимается отношение суммарной величины значений водопритоков (водопоглощений) отдельных зон к суммарной раскрытой мощности соответствующего стратиграфического подразделения. Однако при этом по относительной водообильности явно выделяются райккюлаский горизонт и адилаская пачка пиргуского горизонта.

Вообще водообильность карбонатных пород очень разнообразна; что обусловлено различиями в их вещественном составе; структуре и текстуре, различными степенью и характером трещиноватости; кавернозно- 
Распределение зон водопритоков (водопоглощения) по исследованным стратиграфическим подразделениям

\begin{tabular}{|c|c|c|c|c|c|c|}
\hline \multirow{2}{*}{$\begin{array}{c}\text { Стратигра- } \\
\text { фическое } \\
\text { подразделение }\end{array}$} & \multicolumn{3}{|c|}{$\begin{array}{c}\text { Количество пройденных } \\
\text { скважин }\end{array}$} & \multicolumn{3}{|c|}{$\begin{array}{c}\text { Изученная суммарная } \\
\text { мощность, \% }\end{array}$} \\
\hline & общее & $\begin{array}{c}\text { с зонами } \\
\text { водопри- } \\
\text { токов }\end{array}$ & $\%$ & общая & $\begin{array}{l}\text { зон } \\
\text { водопри- } \\
\text { токов }\end{array}$ & $\%$ \\
\hline $\begin{array}{l}\mathrm{S}_{1} \text { rk } \\
\mathrm{S}_{1} \text { jurKr } \\
\mathrm{S}_{1} \text { jurTm } \\
\mathrm{S}_{1} \text { jurV }+\mathrm{K} \\
\mathrm{O}_{3} \text { pr } \\
\mathrm{O}_{3} \text { prgA } \\
\mathrm{O}_{3} \text { prgM } \\
\mathrm{O}_{3} \mathrm{Vr} \\
\mathrm{O}_{3} \mathrm{nb}-\mathrm{O}_{2} \text { jh }\end{array}$ & $\begin{array}{l}18 \\
22 \\
28 \\
36 \\
29 \\
18 \\
14 \\
8 \\
8\end{array}$ & $\begin{array}{r}17 \\
9 \\
16 \\
28 \\
10 \\
15 \\
7 \\
3 \\
2\end{array}$ & $\begin{array}{l}95 \\
41 \\
57 \\
78 \\
35 \\
83 \\
50 \\
38 \\
25\end{array}$ & $\begin{array}{r}258,9 \\
96,4 \\
150,1 \\
419,1 \\
195,1 \\
190,7 \\
294,5 \\
90,2 \\
180,6\end{array}$ & $\begin{array}{r}61,0 \\
13,2 \\
24,8 \\
75,0 \\
32,8 \\
36,4 \\
18,0 \\
8,0 \\
8,8\end{array}$ & $\begin{array}{r}23,6 \\
13,7 \\
16,5 \\
17,9 \\
16,8 \\
19,1 \\
6,1 \\
8,9 \\
4,9\end{array}$ \\
\hline Итого & & & & 1875,6 & 278,0 & 14,8 \\
\hline
\end{tabular}

сти и закарстованности пород. До последнего времени водообильность карбонатных пород связывалась больше всего с их вещественным составом (Верте, 1965; Иыгар, 1974). Водообильными считались карбонатные породы, свободные от разных примесей. Мергели и глинистые известняки с прослойками мергеля считались водоупорами. Однако собранный нами с помощью расходометрии фактический материал не подтверждает это. Наши исследования показывают, что водопритоки в скважины поступают из всех разновидностей пород. Наиболее часто водоносные слои располагаются на контактах литологических разновидностей пород. Связано это, по-видимому, с более слабыми контактами между породами различного литологического состава. По всей вероятности, именно такие поверхности (трещины) напластования представляют собой водоносные слои, с наличием которых связаны основные водопритоки в скважины. Можно предполагать, что под влиянием тектонических процессов наибольшие подвижки (отслоение и т. п.) происходили на контактах слоев с разными механическими свойствами.

Относительно слабые контакты между плотными известняками и прослоями мергеля имеются, например, в разрезе варболаской пачки. При неглубоком залегании мергели как малоустойчивые породы могут подвергаться суффозионным процессам, в результате которых в разрезе образуются водоносные трещины. Из вышесказанного следует очень важная роль текстурных особенностей пород, на что ранее внимания не обращалось.

Большое значение при распределении водоносных слоев имеет глубина залегания отдельных стратиграфических подразделений. Поэтому в пределах своих выходов, которые прослеживаются севернее описываемой территории, некоторые из выделенных слабопроницаемых стратиграфических подразделений становятся водоносными. Наоборот, с увеличением глубины залегания уменьшаются трещиноватость и закарстованность, определяющие фильтрационные свойства карбонатных пород.

Мощность зоны наибольшей трещиноватости и обводненности составляет около 75 м. На'эту часть разреза падает около $97 \%$ среднего водопритока карбонатной толщи (рис. 4е). На глубине 75-140 м зарегистрированы лишь отдельные водопритоки. 


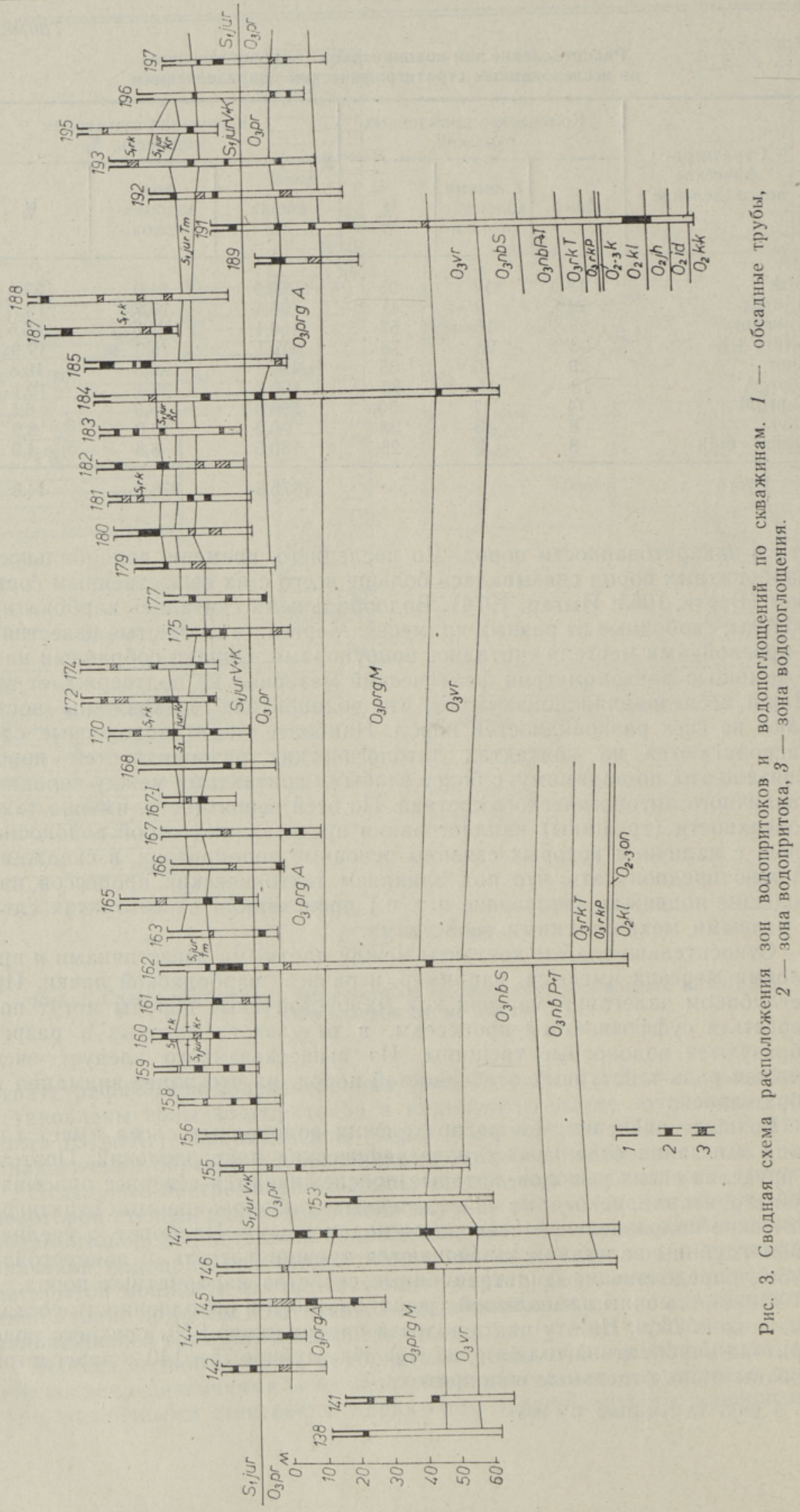



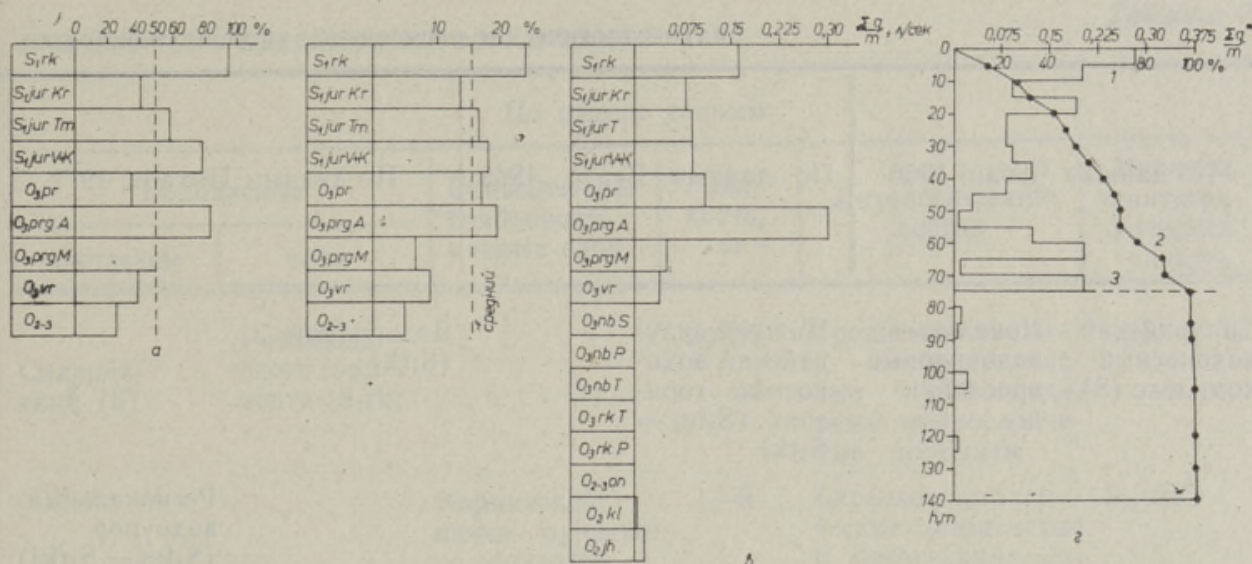

Рис. 4. Обобщенные результаты расходометрических исследований: $a$ - эпюра количества скважин с зонами водопритока (водопоглощения), б - эпюра относительной мощности зон водопритоков (водопоглощений), в - эпюра обобщенных водопритоков (водопоглощений), г - эпюра поинтервальных обобщенных водопритоков (водопоглощений) (1), график водообильности (2) и граница наиболее обводненной толщи (3).

По относительной водообильности силурийско-ордовикскую карбонатную толщу можно в пределах изученной территории подразделить на ряд водоносных и относительно водоупорных слоев (табл. 2), которые описаны ниже.

Водоносные слои райккюлаского горизонта $\left(\mathrm{S}_{1} \mathrm{rk}\right)$ приурочены к доломитам и доломитистым известнякам, которые широко распространены в южной части изученной территории. В естественных условиях водоносные слои (зоны) разделяются на водоотдающие и водопоглощающие. Наличие в скважинах одного горизонта одновременно как водопоглощающих, так и водоотдающих слоев (зон) указывает на различия в пьезометрических уровнях отдельных водоносных слоев в пределах ограниченных территорий. Наиболее высокие значения обобщенных водопритоков $(0,1-0,3$ л/сек) отмечены в районе тектонических нарушений Пеэтри-Эсна (см. рис. 1).

Средний обобщенный водоприток 18 скважин составляет $0,16 \Omega / c е \kappa$.

Относительно слабопроницаемые слои каринуской пачки юуруского горизонта ( $\left.\mathrm{S}_{1} \mathrm{jurKr}\right)$ представлены на большей части участка почти чистыми детритистыми известняками. Водопритоки установлены в 9 скважинах из 22 исследованных, т. е. составляют $41 \%$. Мощность водоносных слоев равняется $13,7 \%$ суммарной мощности исследованного расходометрией разреза. Скважины с водопритоками из каринуской пачки сконцентрированы в меридиональной полосе от д. Валасте до д. Пеэтри, ширина которой $3-5$ км. На остальной территории водопритоки в скважины отсутствуют (см. рис. 1).

Водоносны е слои юуруского горизонта ( $\left.\mathrm{S}_{1} \mathrm{jur}\right)$ приурочены к таммикуской, варболаской и койгиской пачкам юуруского горизонта. Несмотря на значительную изменчивость литологического состава при вскрытии этих подразделений, скважин с водопритоками явно больше, чем скважин, из которых водопритоков не отмечалось. В таммикуской пачке количество скважин с водопритоками составляет 57, в варболаско-койгиской - 78\%. Обобщенные водопритоки в основном составляют $0,01-0,1 л / с е \kappa$. Хотя в целом описываемые пачки характеризуются как водоносные, отмечаются некоторые участки, в пределах которых 
Гидрогеологическое расчленение карбонатной толщи

По данным Чебан, 1966

По данным Верте, 1965

По данным Иыгара, 1977

Региональный водоупор

Силурийский водоносный

Локальные водоупорные комплекс (S) прослойки
Нижний силурийский водоносный горизонт $\left(\mathrm{S}_{1} \mathrm{tm}-\right.$ $\left.\mathrm{S}_{1} \mathrm{rk}\right)$
Водоносный $\left(\mathrm{S}_{1} \mathrm{rk}\right)$

\section{Водоупор ( $\mathrm{S}_{\mathrm{I}}$ jurV)}

Верхний ордовикскнй водоносный горизонт $\left(\mathrm{O}_{3} \mathrm{rk}-\mathrm{O}_{3} \mathrm{pk}\right)$
Ордовикский водоносный комплекс $\left(\mathrm{O}_{3} \mathrm{pr}-\mathrm{O}_{3} \mathrm{kn}\right)$

$\left(\mathrm{S}_{1} \mathrm{tm}-\mathrm{S}_{1} \mathrm{rkI}\right)$

Водоносный $\left(\mathrm{S}_{1} \mathrm{tm}-\mathrm{S}_{\mathrm{I}} \mathrm{jr}\right)$

Локальный водоупор $\left(\mathrm{S}_{1} \mathrm{jur}\right)$

Водоносный $\left(\mathrm{O}_{3} \mathrm{pk}-\mathrm{O}_{3} \mathrm{pg}\right)$
Локальный водоупор $\left(\mathrm{O}_{3} \mathrm{pg} \mathrm{A}\right)$

Региональный водоупор $\left(\mathrm{O}_{3} \mathrm{vr}-\mathrm{O}_{3}\right.$ pg.M $)$

Водоносный Локальный $\left(\mathrm{O}_{3} \mathrm{rk}-\mathrm{O}_{3} \mathrm{nb}\right)$ водоупор $\left(\mathrm{O}_{3} \mathrm{nb}\right)$

водопритоков в скважины не установлено. В таммикуской пачке такая зона протягивается от Ярва-Яани до д. Пеэтри. Отсутствием водоносных слоев выделяется также варболаская пачка южнее и восточнее линии Эсна-Пеэтри (см. рис. 1).

Относительно слабопроницаемые слои поркуни с кого горизонта $\left(\mathrm{O}_{3} \mathrm{pr}\right)$ имеют почти повсеместное распространение. Из 29 исследованных скважин водопритоки (водопоглощения) отмечались лишь в 10, что составляет $35 \%$ их количества. Следует отметить, что эти $35 \%$ скважин с водопритоками сконцентрированы на трех небольших по площади участках. Около $90 \%$ территории характеризуется отсутствием водопритоков в скважины (см. рис. 2).

Водоносны е слои адилаской пачки пиргуского горизонта $\left(\mathrm{O}_{3} \mathrm{prgA}\right)$ являются наиболее выдержанным скоплением подземных вод ордовикского водоносного комплекса. Количество скважин с водопритоками составляет $83 \%$ общего количества исследованных скважин. Мощность водоносных зон равняется 19,1\% общей мощности тачки. Средний обобщенный водоприток $(0,30$ л/сек) в $3-6$ раз превышает обобщенные водопритоки других стратиграфических подразделений ордовика (см. рис. 2). Относительно высокая водообильность объясня- 


\begin{tabular}{|c|c|c|c|c|c|}
\hline \multicolumn{6}{|c|}{ По нашим данным } \\
\hline \multicolumn{2}{|c|}{ Водоносные } & \multirow{2}{*}{$\begin{array}{l}\text { Относительно } \\
\text { слабопрони- } \\
\text { цаемые слои }\end{array}$} & \multirow{2}{*}{$\begin{array}{c}\text { Мощ- } \\
\text { ность, } \\
\quad M\end{array}$} & \multirow{2}{*}{$\begin{array}{c}\text { Литологический } \\
\text { состав }\end{array}$} & \multirow{2}{*}{$\begin{array}{c}\text { Индексы } \\
\text { стратигра- } \\
\text { фических } \\
\text { единиц }\end{array}$} \\
\hline комплексы & слон & & & & \\
\hline
\end{tabular}

$\begin{array}{ll}\text { Силурий- } & \text { Райккюла- } \\ \text { ский (S) } & \text { ского гори- } \\ & \left.\text { зона ( } \mathrm{S}_{1} \mathrm{rk}\right)\end{array}$

Юypyckoro
ropизонта
(S,jur)

Ордовикский $(\mathrm{O})$

\begin{tabular}{|c|c|c|c|}
\hline & до 36 & $\begin{array}{l}\text { Среднекомковатые } \\
\text { и -волнистослоис- } \\
\text { тые известняки, } \\
\text { реже микрослойча- } \\
\text { тые доломиты }\end{array}$ & $\mathrm{S}_{1} \mathrm{rk}$ \\
\hline \multirow[t]{2}{*}{$\begin{array}{l}\text { Каринуской } \\
\text { пачки юуруско- } \\
\text { го горизонта } \\
\left(\mathrm{S}_{1} \text { jurKr }\right)\end{array}$} & $1-9$ & $\begin{array}{l}\text { Скрытокристалли- } \\
\text { ческие детритистые } \\
\text { и биоморфные из- } \\
\text { вестняки }\end{array}$ & $\mathrm{S}_{1}$ jurKr \\
\hline & $12-25$ & $\begin{array}{l}\text { Средневолнисто- } \\
\text { слонстые глинис- } \\
\text { тые известняки, ре- } \\
\text { же детритистые и } \\
\text { биоморфные из- } \\
\text { вестняки }\end{array}$ & $\begin{array}{l}S_{1} \text { jurTm } \\
S_{1} \text { jurV }\end{array}$ \\
\hline \multirow[t]{2}{*}{$\begin{array}{l}\text { Поркуниского } \\
\text { горизонта } \\
\left(\mathrm{O}_{3} \mathrm{pr}\right)\end{array}$} & $5-12$ & $\begin{array}{l}\text { Рифовые и чисто } \\
\text { детритовые извест- } \\
\text { няки; песчаники, } \\
\text { доломиты }\end{array}$ & $\mathrm{O}_{3} \mathrm{pr}$ \\
\hline & $5-18$ & $\begin{array}{l}\text { Среднекомковатые } \\
\text { глинистые детри- } \\
\text { тистые известняки }\end{array}$ & $\mathrm{O}_{3} \mathrm{prgA}$ \\
\hline
\end{tabular}

Среднекомковатые $\mathrm{S}_{1} \mathrm{rk}$ и -волнистослоистые известняки, реже микрослойчатые доломиты

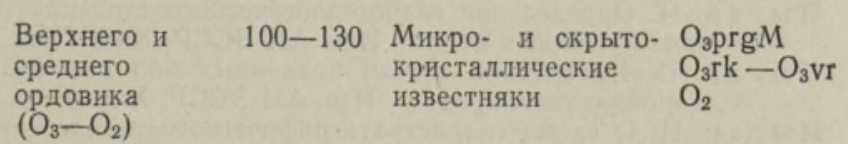

Адилаской пачки пиргуского горизонта $\left(\mathrm{O}_{3}\right.$ prgA $)$

ется, по-видимому, литологическими и текстурными особенностями пачки, которая сложена среднекомковатыми детритистыми глинистыми известняками или глинистыми доломитистыми известняками с прослойками мергеля. Для пачки характерны многочисленные поверхности перерыва.

Относительно слабопроницаемые слои верхнего и с реднего ордовика $\left(\mathrm{O}_{3-2}\right)$ приурочены к скрыто-и микрокристаллическим известнякам набалаского и раквереского горизонтов, моэской пачки пиргуского горизонта и глинистым детритистым известнякам вормсиского горизонта верхнего ордовика и ко всем вскрытым горизонтам среднего ордовика. В пределах изученной глубины гидрогеологического разреза (в среднем до $50 \mathrm{M}$ ) наиболее распространенными по мощности подразделениями являются моэская пачка пиргуского горизонта и вормсиский горизонт. Мощность водоносных зон составляет 6-9\% общей мощности названных подразделений. С увеличением глубины залегания доля водоносных $30 н$ уменьшается до $4,9 \%$. Интересно отметить, что в скв. 191, расположенной в пос. Роозна-Аллику, водопритоки установлены в глинистых известняках кейлаского и йыхвиского горизонтов на глубине $120-130$ м, в то время как чистые скрыто-и микрокристаллические 
известняки раквереского и набалаского горизонтов, залегающие значительно выше, были безводными,

В заключение следует сказать, что

1) водоносность карбонатных пород на Пандивереской возвышенности связана с относительно маломощными зонами, которые могут наблюдаться во всех стратиграфических подразделениях. Бо́льшая часть гидрогеологического разреза карбонатных пород практически безводна;

2) наиболее часто водоносные зоны отмечаются на контактах литологических разновидностей пород, в частности в глинистых комковатых известняках пиргуского и юуруского горизонтов;

3) подтверждается предположение П. Иыгара об условности и невыдержанности отдельных водоносных и водоупорных горизонтов, вследствие чего расчленение гидрогеологического разреза карбонатных пород можно проводить условно и только на основе статистической обработки материала;

4) некоторое отличие от ранее проведенных гидростратиграфикаций (Верте, 1965; Йыгар, 1973, 1974) обусловлено, по-видимому, более точной корреляцией водоносных зон с-геологическим разрезом в ходе расходометрических исследований.

\section{ЛИТЕРА Т Р РА}

А льт о в ски й М. Е. Методические указания по составлению гидрогеологических карт масштабов 1:1000 $000-1: 500000$ и $1: 200000-1: 100000$ м. М., 1960.

В ерте А. Основные черты гидрогеологического строения и формирования подземных вод Эстонского артезианского бассейна. - Изв. АН ЭССР. Сер. бнол., 1965, т. 14 , № 4 , с. $563-586$.

Ге ршанович И. М. Геофизические методы исследования гидрогеологических скважин. - В кн.: Методы геофизики в гидрогеологии и инженерной геологии. М., 1972.

Иыгар П. Определение гидрогеологического строения при помощи суммарных уровней подземных вод. - Изв. АН ЭССР. Хим. Геол., 1973, т. 22, № 4, с. $341-344$.

Пыгар П. Химический состав подземных вод как индикатор водоупорных свойств карбонатных пород. - Изв. АН ЭССР. Хим. Геол., 1974, т. 23, № 2, с. $161-166$.

П ыг ар П. О схеме гидростратиграфического расчленения карбонатных пород Северной Эстонии. - Изв, АН ЭССР. Хим. Геол., 1977, т. 26, № 2, с. 155-158.

Плотников И. И. Опыт применения расходометрии скважин при гидрогеологических исследованиях на СУБР. - В кн.: Прогноз водопритоков в горные выработки и водозаборы подземных вод в трещиноватых и закарстованных породах. Недра, М., 1972.

Че б а н Э. Р. Характеристика водоносных комплексов горизонтов и водоупорных толщ. - В кн.: Гидрогеология СССР. М., 1966, т. ХХX.

Управление геологии

Совета Министров ЭССР
Поступила в редакцию 28/VI 1977

\section{R. PERENS}

\section{PANDIVERE KÕRGUSTIKU KARBONAATSETE KIVIMITE KIHTKONNA HUDROGEOLOOGILINE LIIGENDAMINE PUURAUGUSISESTE VOOLUHULKADE MOOTMISE TEEL}

Artiklis on käsitletud vettkandva kihtkonna stratifitseerimist deebitite môōtmise alusel puuraukude lahtistes vahemikes. Analüüsitud on 43 Pandivere kõrgustikul paikneva puuraugu andmeid. Vettkandvad ja vett suhteliselt vähe juhtivad kihid on eristatud üksikute stratigraafiliste üksuste kohta arvutatud keskmiste vooluhulkade ning veetsoonide sageduse ja nende suhtelise paksuse alusel. Kuigi üksikuid veetsoone leidub kōigis stratigraa- 
filistes üksustes, on vettkandvateks kihtideks loetud neid üksusi, kus veetsoone on rohkem kui pooltes puuraukudes. Kôige sagedamini esineb veetsoone erineva litoloogilise koostisega kivimite kokkupuutekohtades ja suhteliselt savikates mugulja tekstuuriga pirgu ja juuru lademe kivimeis.

\section{R. PERENS}

\section{HYDROGEOLOGICAL GROUPING OF CARBONATE ROCKS OF PANDIVERE UPLAND BY MEASURING FLOW AMOUNTS IN BOREHOLES}

The author discusses the stratification of water-bearing strata on the basis of measuring the flow debits in the open intervals between the boreholes. The data of 43 boreholes situated in Pandivere Upland have been analysed. The water-bearing and the relatively less water-conducting beds have been differentiated in separate stratigraphical units on the bases of the calculation of mean flow amounts, frequency of water zones and their relative thicknesses. Though some single water zones occur in almost all the stratigraphical units, nevertheless only those beds have been considered water-bearing, in which water zones occur in more than a half of the boreholes. The water zones occur with the greatest frequency in the contact zones of rocks of different lithological composition and in rocks of a relatively clayey tuberous texture, e. g., in Pirgu and Juuru stages. 